\title{
Senolytic compounds control a distinct fate of androgen receptor agonist- and antagonist-induced cellular senescent LNCaP prostate cancer cells
}

Thanakorn Pungsrinont ${ }^{1}$, Malika Franziska Sutter ${ }^{1,2+}$, Maren C. C. M. Ertingshausen ${ }^{1 \dagger}$, Gopinath Lakshmana', Miriam Kokal ${ }^{1}$, Amir Saeed Khan ${ }^{1,3}$ and Aria Baniahmad ${ }^{1 *}$

\begin{abstract}
Background: The benefit of inducing cellular senescence as a tumor suppressive strategy remains questionable due to the senescence-associated secretory phenotype. Hence, studies and development of senolytic compounds that induce cell death in senescent cells have recently emerged. Senescent cells are hypothesized to exhibit different upregulated pro-survival/anti-apoptotic networks depending on the senescent inducers. This might limit the effect of a particular senolytic compound that targets rather only a specific pathway. Interestingly, cellular senescence in prostate cancer (PCa) cells can be induced by either androgen receptor (AR) agonists at supraphysiological androgen level (SAL) used in bipolar androgen therapy or by AR antagonists. This challenges to define ligand-specific senolytic compounds.

Results: Here, we first induced cellular senescence by treating androgen-sensitive PCa LNCaP cells with either SAL or the AR antagonist Enzalutamide (ENZ). Subsequently, cells were incubated with the HSP90 inhibitor Ganetespib (GT), the BCl-2 family inhibitor ABT263, or the Akt inhibitor MK2206 to analyze senolysis. GT and ABT263 are known senolytic compounds. We observed that GT exhibits senolytic activity specifically in SAL-pretreated PCa cells. Mechanistically, GT treatment results in reduction of AR, Akt, and phospho-S6 ( $p-S 6$ ) protein levels. Surprisingly, ABT263 lacks senolytic effect in both AR agonist- and antagonist-pretreated cells. ABT263 treatment does not affect AR, Akt, or S6 protein levels. Treatment with MK2206 does not reduce AR protein level and, as expected, potently inhibits Akt phosphorylation. However, ENZ-induced cellular senescent cells undergo apoptosis by MK2206, whereas SAL-treated cells are resistant. In line with this, we reveal that the pro-survival p-S6 level is higher in SAL-induced cellular senescent PCa cells compared to ENZ-treated cells. These data indicate a difference in the agonist- or antagonist-induced cellular senescence and suggest a novel role of MK2206 as a senolytic agent preferentially for AR antagonist-treated cells.
\end{abstract}

Conclusion: Taken together, our data suggest that both AR agonist and antagonist induce cellular senescence but differentially upregulate a pro-survival signaling which preferentially sensitize androgen-sensitive PCa LNCaP cells to a specific senolytic compound.

\footnotetext{
*Correspondence: aria.baniahmad@med.uni-jena.de

${ }^{\dagger}$ Malika Franziska Sutter and Maren C.C.M Ertingshausen equally contributed

${ }^{1}$ Institute of Human Genetics, Jena University Hospital, Am Klinikum 1 , 07740 Jena, Germany

Full list of author information is available at the end of the article
}

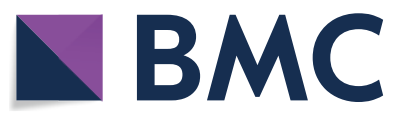

(c) The Author(s) 2020. This article is licensed under a Creative Commons Attribution 4.0 International License, which permits use, sharing, adaptation, distribution and reproduction in any medium or format, as long as you give appropriate credit to the original author(s) and the source, provide a link to the Creative Commons licence, and indicate if changes were made. The images or other third party material in this article are included in the article's Creative Commons licence, unless indicated otherwise in a credit line to the material. If material is not included in the article's Creative Commons licence and your intended use is not permitted by statutory regulation or exceeds the permitted use, you will need to obtain permission directly from the copyright holder. To view a copy of this licence, visit http://creativeco mmons.org/licenses/by/4.0/. The Creative Commons Public Domain Dedication waiver (http://creativecommons.org/publicdomain/ zero/1.0/) applies to the data made available in this article, unless otherwise stated in a credit line to the data. 
Keywords: Prostate cancer, Cellular senescence, Senolytic compounds, HSP90 inhibitor, Bcl-2 family inhibitor, Akt inhibitor, Bipolar androgen therapy, Antiandrogen

\section{Background}

For decades, prostate cancer $(\mathrm{PCa})$ ranks the most diagnosed cancer and the second leading cause of cancer-related deaths of men in Western countries $[1,2]$. It is well known that the androgen-activated androgen receptor (AR) plays a critical role for the growth of both normal and cancerous prostate [3]. Therefore, androgen deprivation therapy and inhibition of the ARsignaling by AR antagonists are the major forms of $\mathrm{PCa}$ hormone therapy. However, after a period of time, the cancer becomes resistant through adaptive responses of AR-signaling and activation of other signaling mechanisms [4-6]. Interestingly, supraphysiological androgen levels (SAL) are used in clinical trials so-called bipolar androgen therapy (BAT) as another approach to AR antagonists [7, 8].

We have previously described that cellular senescence can be induced by AR-signaling in PCa. On the one hand, several AR antagonists such as atraric acid, compound $\mathrm{C} 28$, or aminosteroids have been shown to induce cellular senescence in PCa cells [9-11]. On the other hand, induction of cellular senescence by supraphysiological level of AR agonists, the natural androgen dihydrotestosterone (DHT) or the less metabolized synthetic androgen methyltrienolone (R1881), were also described [12, 13]. Moreover, cellular senescence was induced in PCa samples from patients with prostatectomy ex vivo [13].

Cellular senescence is initially defined as an irreversible cell cycle arrest and has been proposed as one of the cancer inhibition strategies $[14,15]$. However, the benefit of cellular senescence induction remains controversial. Although senescent cells can no longer divide, they are metabolically active and secrete cytokines, chemokines, growth factors, and proteinases known as the senescence-associated secretory phenotype (SASP). The SASP can mediate paracrine effects on neighboring non-senescent tumor cells and thus might act as a tumor promoter [16-19]. Therefore, induction of cellular senescence in cancer cells and elimination of these cells by senolytic compounds might be very useful to treat cancer.

Senolytic agents are molecular compounds that induce cell death in senescent cells [20]. Senescent cells might have an upregulated pro-survival/antiapoptotic network, e.g. PI3K/Akt and/or Bcl-2/Bcl-xL pathway. Senolytic agents such as the HSP90 inhibitor Ganetespib (GT) and the Bcl-2 family inhibitor
ABT263 have been described [21-23]. Notably, different senescence inducers might cause senescent cells to express a distinct upregulated pro-survival/anti-apoptotic pathway [24]. This might limit the ability of a particular senolytic agent that target specifically only one of these pathways.

In this study, we first induced cellular senescence in androgen-sensitive $\mathrm{PCa} \mathrm{LNCaP}$ cells by treating with either AR agonist at SAL or antagonist, and subsequently analyzed the senolytic effects of GT, ABT263, and the highly selective allosteric Akt inhibitor MK2206. Our data suggest that the pro-survival Akt-S6 signaling is more active in AR agonist-induced cellular senescent cells than antagonist. Interestingly, treatment with GT or MK2206 after AR ligand-induced cellular senescence exhibits distinct senolytic activities depending on the type of AR ligand, agonist or antagonist, whereas ABT263 lacks senolytic activity.

\section{Results \\ AR agonist and antagonist induce cellular senescence and suppress $\mathrm{LNCaP}$ cell growth}

In order to analyze the activity of senolytic agents in senescent LNCaP cells, first, cellular senescence was induced in the PCa cell line LNCaP cells by treating with AR agonist at SAL or antagonist for $72 \mathrm{~h}$ as described earlier [9, 13] (Fig. 1a, b). Thereafter, cells were treated with senolytic compounds to analyze cell growth, apoptosis, necroptosis and senescence markers. Since DHT can be rapidly metabolized and the metabolites can activate the estrogen receptor beta [25], the more stable and AR-specific compound R1881 was used as an AR agonist. As AR antagonist, the clinically approved Enzalutamide (ENZ) was used.

We have previously reported the capability of R1881 to induce cellular senescence in PCa cells [13]. Here, we show that the treatment with ENZ can also induce cellular senescence in LNCaP cells (Fig. 1a, b). In line with this, a significant increase of the senescence regulator CDKN2A (p16 $\left.{ }^{\text {INK4a }}\right)$ mRNA was detected by ENZ treatment (Additional file 1: Fig. S1). Interestingly, a significant growth suppression of LNCaP cells after withdrawal of $A R$ agonist or antagonist was observed (Fig. 1c). Moreover, we could not detect cleaved PARP, a marker for apoptosis, after AR ligand treatment (Fig. 1d), suggesting that AR ligands do not induce apoptosis but rather senescence in LNCaP cells. Thus, 

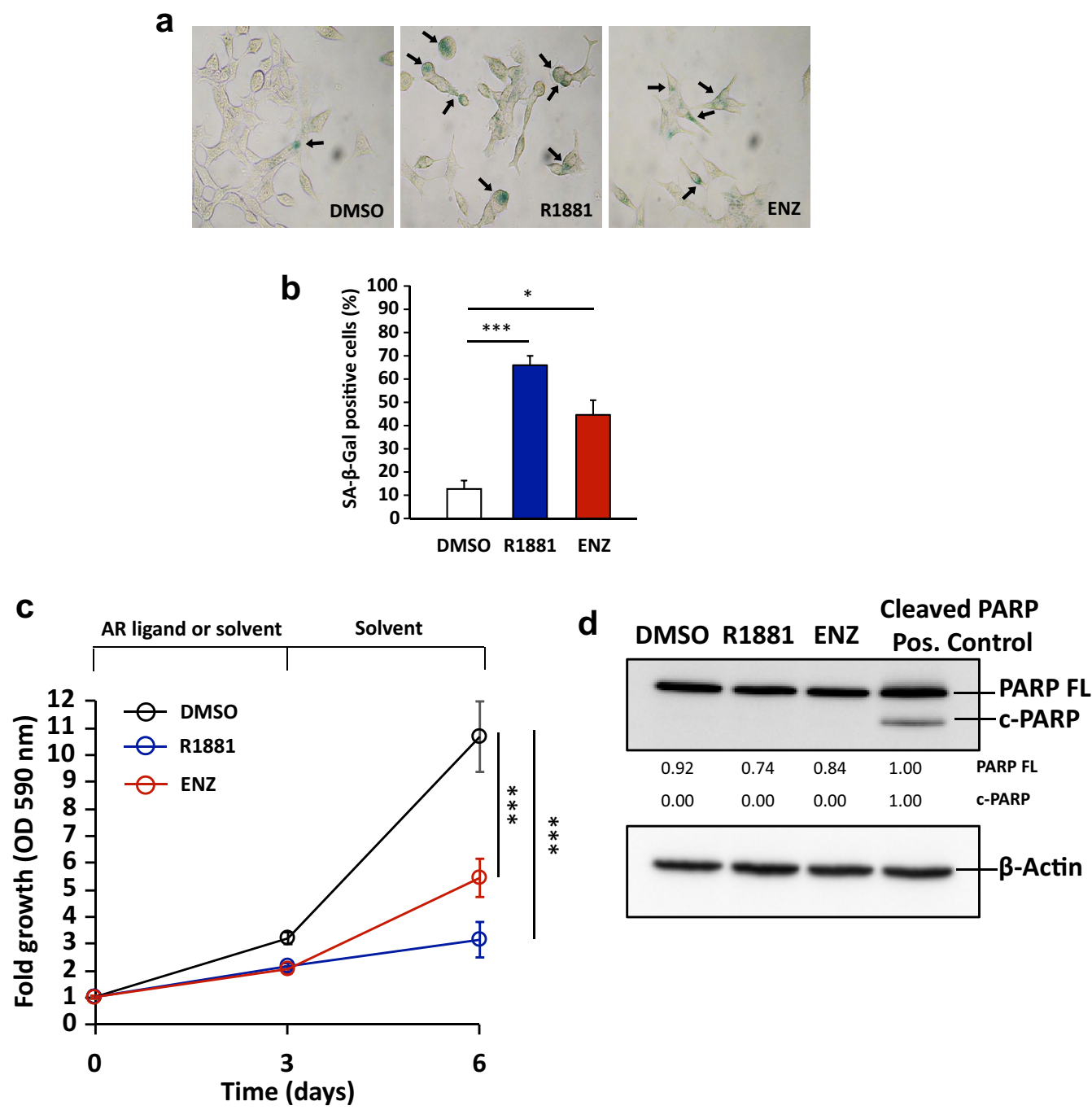

Fig. 1 AR agonist and antagonist induce cellular senescence and suppress PCa LNCaP cell growth. LNCaP cells were treated for $72 \mathrm{~h}$ with $1 \mathrm{nM}$ R1881 (agonist), $10 \mu \mathrm{M}$ ENZ (antagonist), or $0.1 \%$ DMSO as solvent control. After that, the AR ligands were removed. Fresh medium with $0.1 \%$

DMSO was added and further incubated for additional $72 \mathrm{~h}$. a Representative pictures of SA- $\beta$-Gal staining under light microscope. Arrows indicate SA- $\beta$-Gal positive stained cells. $\mathbf{b}$ Percentage of SA- $\beta$-Gal positive stained cells at $72 \mathrm{~h}$ of AR ligand treatment. Bar graphs are shown as mean \pm SEM $(n=3)$. c Growth curves of LNCaP cells with indicated treatments and time points analysed by crystal violet staining and OD $590 \mathrm{~nm}$ measurement. Values obtained from day 0 were set arbitrarily as 1. Line graphs are shown as mean \pm standard deviation $(n=5)$. d The protein extraction was performed after $72 \mathrm{~h}$ of AR ligand treatment. To detect cleaved PARP (c-PARP), protein extracted from LNCaP cells treated with $1 \mu \mathrm{M}$ Akt inhibitor (MK2206) was loaded as positive control. Full-length PARP (PARP FL) and c-PARP were detected by Western blotting and normalized to $\beta$-Actin levels served as loading control. Upper and lower numbers indicate normalized PARP FL and c-PARP band intensities relative to positive control

the data suggest that both AR agonist and antagonist induce cellular senescence leading to growth suppression of LNCaP cells.

\section{HSP90 inhibitor enhances apoptosis of AR agonist-induced} cellular senescent LNCaP cells

Both the HSP90 inhibitor GT and the Bcl-2 family inhibitor ABT263 have been described as senolytic agents $[21-23,26]$. Here, we show that both compounds inhibit
LNCaP cell proliferation and induce apoptosis at higher concentrations (Additional file 1: Fig. S2). Notably, the growth inhibition and apoptosis induction by GT were observed after $48 \mathrm{~h}$ of treatment, whereas ABT263- or MK2206-induced apoptosis was detected after $24 \mathrm{~h}$ of treatment (Additional file 1: Fig. S2).

To analyze senolytic activity of GT and ABT263 after cellular senescence was induced by SAL or ENZ treatment, $25 \mathrm{nM}$ GT and $1 \mu \mathrm{M}$ ABT263 were employed. 


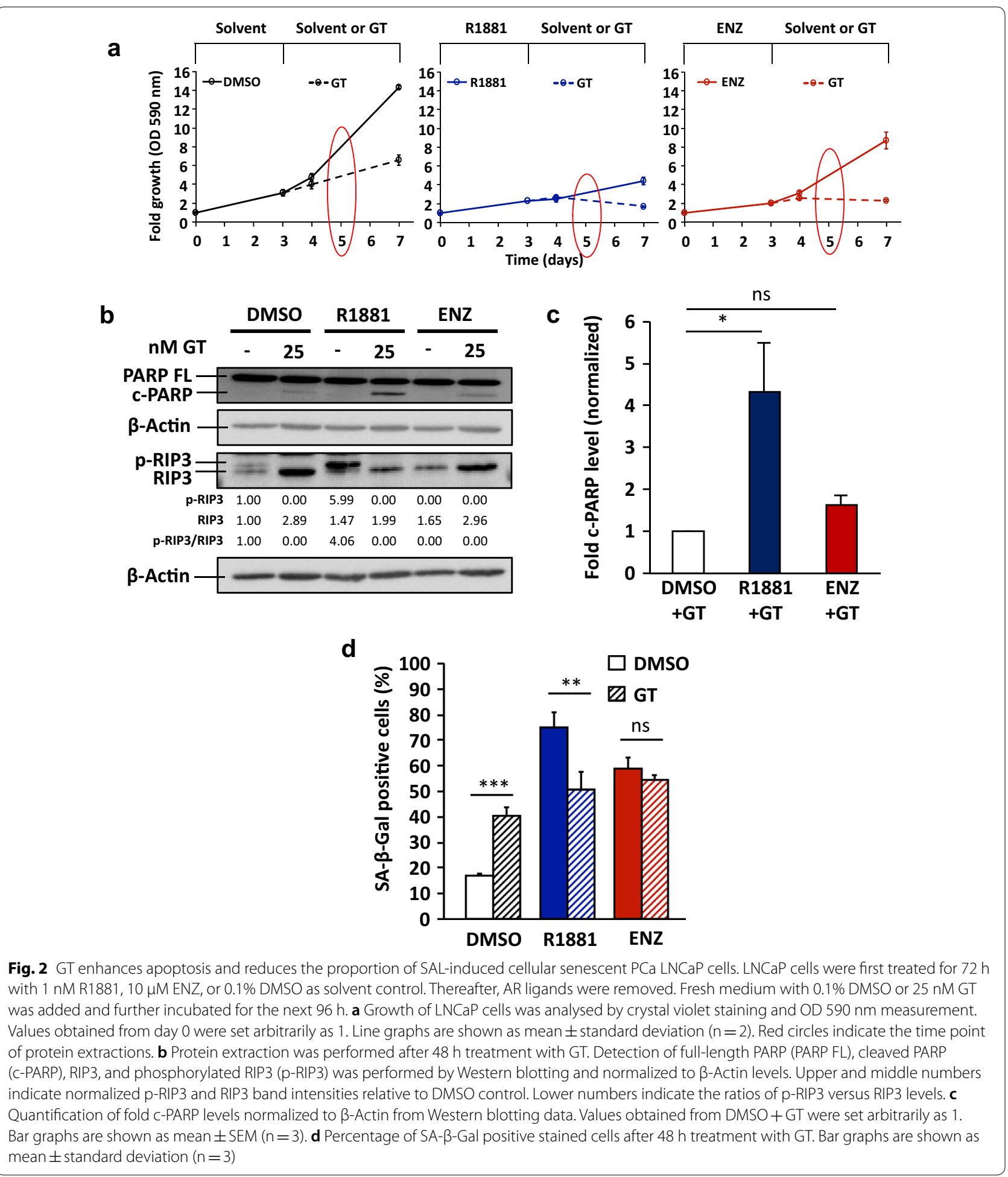

Interestingly, GT treatment further suppressed cell growth after induction of cellular senescence by AR ligand (Fig. 2a). Detection of cleaved PARP indicates that GT treatment alone induces apoptosis and is more potent when cells are pretreated with SAL (Fig. 2b). Additionally, we analyzed necroptosis, another type of programmed cell death [27], by detecting the specific marker phosphoRIP3 (p-RIP3) (Fig. 2b and Additional file 1: Fig. S3). GT 
treatment with or without pretreatment with AR ligands reduces p-RIP3 level (Fig. 2b), suggesting that necroptosis is not the underlying mechanism of GT-induced cell death.

Prominently, GT treatment significantly enhanced cleaved PARP level after AR agonist-induced cellular senescence (Fig. 2b, c) indicating a senolytic activity of GT preferentially for SAL-treated cells. In line with this, we observed an enhanced detachment of cells and significant reduced percentage of SA- $\beta$-Gal positive cells by GT treatment after AR agonist-induced cellular senescence (Fig. 2d and Additional file 1: Fig. S4). Taken together, the results suggest that the known senolytic agent GT enhances apoptosis and further inhibits the growth of AR agonist-induced cellular senescent LNCaP cells.

\section{Treatment with $\mathrm{Bcl}-2$ family inhibitor lacks senolytic} activity in AR ligand-induced cellular senescent LNCaP cells Similar to GT treatment, LNCaP cell growth is suppressed by ABT263 (Fig. 3a), albeit less effective as GT. ABT263 treatment induces cleaved PARP and reduces p-RIP3 levels, indicating that ABT263 can induce apoptosis but not necroptosis (Fig. 3b). However, it is surprising that treatment with ABT263 after either AR agonist- or antagonist-induced cellular senescence exhibits significantly less cleaved PARP than the control-treated cells (Fig. 3b, c). Therefore, the data suggest that AR ligandinduced senescent $\mathrm{LNCaP}$ cells are more resistant to apoptosis induction by ABT263 than non-senescent cells.

Despite less detected cleaved PARP upon ABT263, we observed detachment of cells and reduced percentage of senescent/SA- $\beta$-Gal positive cells in AR ligand-pretreated cells (Fig. 3d and Additional file 1: Fig. S5). These data suggest that ABT263 causes cells to detach rather than to undergo apoptosis after AR agonist or antagonist treatment. Taken together, the results indicate that ABT263 might not have senolytic effect in AR ligandinduced cellular senescent PCa LNCaP cells.

\section{AR antagonist-induced cellular senescent LNCaP cells are sensitive to apoptosis induction by Akt inhibitor}

It is known that activated Akt-signaling is one of the major cellular signaling pathways for cell survival in cancer [28]. MK2206 is a highly selective allosteric Akt inhibitor [29], which has been used in clinical studies against advanced solid tumors [30, 31]. Although MK2206 has also been used thoroughly for PCa cells in many studies [32-35], yet, the information of MK2206 activity for senescent cells is limited. Also, to our knowledge, it has not yet been described as a senolytic agent. Similar to the previous experiments, to analyze whether MK2206 mediates senolytic activity, cellular senescence was first induced by AR ligands and thereafter cells were treated with MK2206.

The results show that MK2206 inhibits cell proliferation in a concentration-dependent manner in the absence of AR ligand pretreatment (Additional file 1: Fig. S2). LNCaP cell growth is suppressed by MK2206 (Fig. 4a). In line with this, induced cleaved PARP but reduced p-RIP3 levels are observed at $24 \mathrm{~h}$ by MK2206 treatment with or without AR ligand pretreatment (Fig. 4b), suggesting that MK2206 induces rather apoptosis but not necroptosis.

Interestingly, detected cleaved PARP is significantly enhanced by MK2206 specifically after ENZ-induced cellular senescence (Fig. 4b, c). Furthermore, an enhanced detachment of cells by MK2206 after ENZ treatment was also observed (Additional file 1: Fig. S5). In contrast, AR agonist-induced cellular senescence exhibits significantly reduced cleaved PARP by MK2206 treatment indicating a protective mechanism against this Akt inhibitor by SAL (Fig. 4b, c). These results indicate that AR antagonist-treated cells are sensitive to MK2206 treatment and suggest MK2206 is an antagonist-specific senolytic compound, whereas agonist-treated cells are resistance.

An increased level of SA- $\beta$-Gal positive cells by MK2206 was observed in the control without pretreatment with AR ligand (Fig. 4d). This suggests that MK2206 is capable of inducing cellular senescence being in line with Xie et al. (2018) [26]. Surprisingly, by analyzing adherent cells, no reduction of SA- $\beta$-Gal positive cells by MK2206 after ENZ-induced cellular senescence was observed (Fig. 4d). We hypothesize that treatment with MK2206 on one hand triggered apoptosis and detachment of ENZ-induced cellular senescent cells and on the other hand induced cellular senescence in the remaining adherent cells (Fig. 4e). Hence, it resulted in an unchanged/compensated percentage level of SA- $\beta$-Gal positive cells.

Taken together, the data indicate that ENZ-induced cellular senescent $\mathrm{LNCaP}$ cells are sensitive to apoptosis induction by MK2206, whereas SAL-induced cellular senescent cells exhibit resistance. Therefore, the results suggest a novel role of MK2206 as a senolytic agent for AR antagonist-treated LNCaP cells.

\section{MK2206 and GT inhibit Akt-signaling, while ABT263 exhibits no effect}

We hypothesized that AR agonist- and antagonistinduced cellular senescence upregulates different prosurvival/anti-apoptotic pathways. To address this, first the expression of Bcl-2 family members BCL2, BCL2L2 and BCL2L1 (encoding BCL-2, BCL-W, and BCL-XL) were analyzed. The results show that specifically agonist treatment significantly downregulates $B C L 2$ and upregulates BCL2L1 mRNA expression (Additional file 1: Fig. 

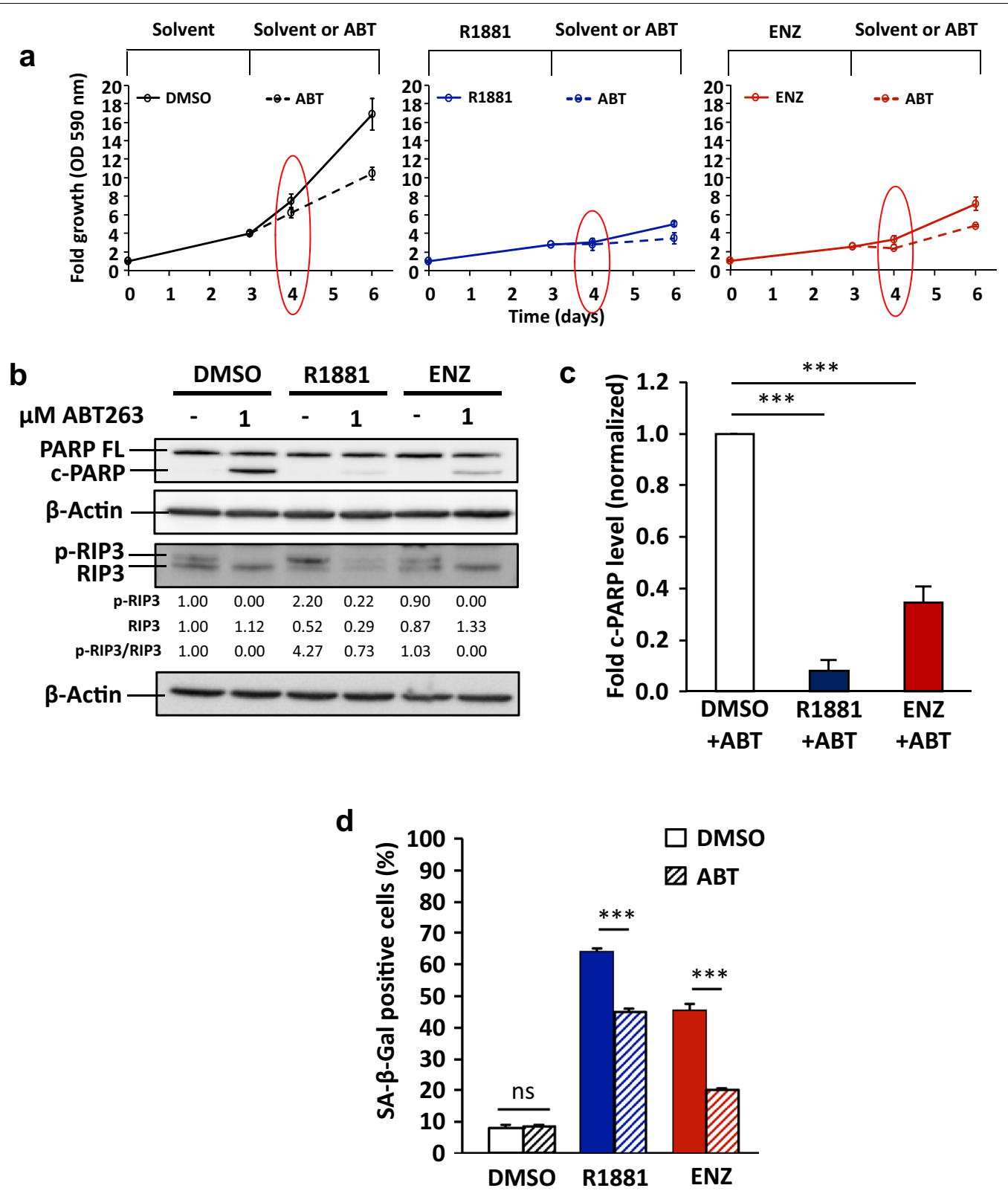

Fig. 3 Treatment with ABT263 lacks senolytic effect in AR ligand-induced cellular senescent PCa LNCaP cells. LNCaP cells were first treated for $72 \mathrm{~h}$ with $1 \mathrm{nM} \mathrm{R1881,10 \mu M} \mathrm{ENZ,} \mathrm{or} \mathrm{0.1 \%} \mathrm{DMSO} \mathrm{as} \mathrm{solvent} \mathrm{control.} \mathrm{After} \mathrm{that,} \mathrm{the} \mathrm{AR} \mathrm{ligands} \mathrm{were} \mathrm{removed.} \mathrm{Fresh} \mathrm{medium} \mathrm{with} 0.1 \%$ DMSO or $1 \mu \mathrm{M}$ ABT263 was added and further incubated for additional $72 \mathrm{~h}$. a Growth of LNCaP cells was analysed by crystal violet staining and OD $590 \mathrm{~nm}$ measurement. Values obtained from day 0 were set arbitrarily as 1. Line graphs are shown as mean \pm standard deviation $(n=2)$. Red circles indicate the time point where protein extraction was performed. $\mathbf{b}$ The protein extraction was performed after $24 \mathrm{~h}$ treatment with ABT263. Detection of full-length PARP (PARP FL), cleaved PARP (c-PARP), RIP3, and phosphorylated RIP3 ( $p$-RIP3) was performed by Western blotting and normalized to $\beta$-Actin levels. Upper and middle numbers indicate normalized $p$-RIP3 and RIP3 band intensities. Lower numbers indicate the ratios of $p$-RIP3 versus RIP3 levels. c Quantification of fold c-PARP levels normalized to $\beta$-Actin from Western blotting data. Values obtained from DMSO + ABT were set arbitrarily as 1. Bar graphs are shown as mean \pm SEM $(n=3)$. $\mathbf{d}$ Percentage of SA- $\beta$-Gal positive stained cells after $24 \mathrm{~h}$ treatment with ABT263. Bar graphs are shown as mean $\pm \operatorname{SEM}(n=3)$ 

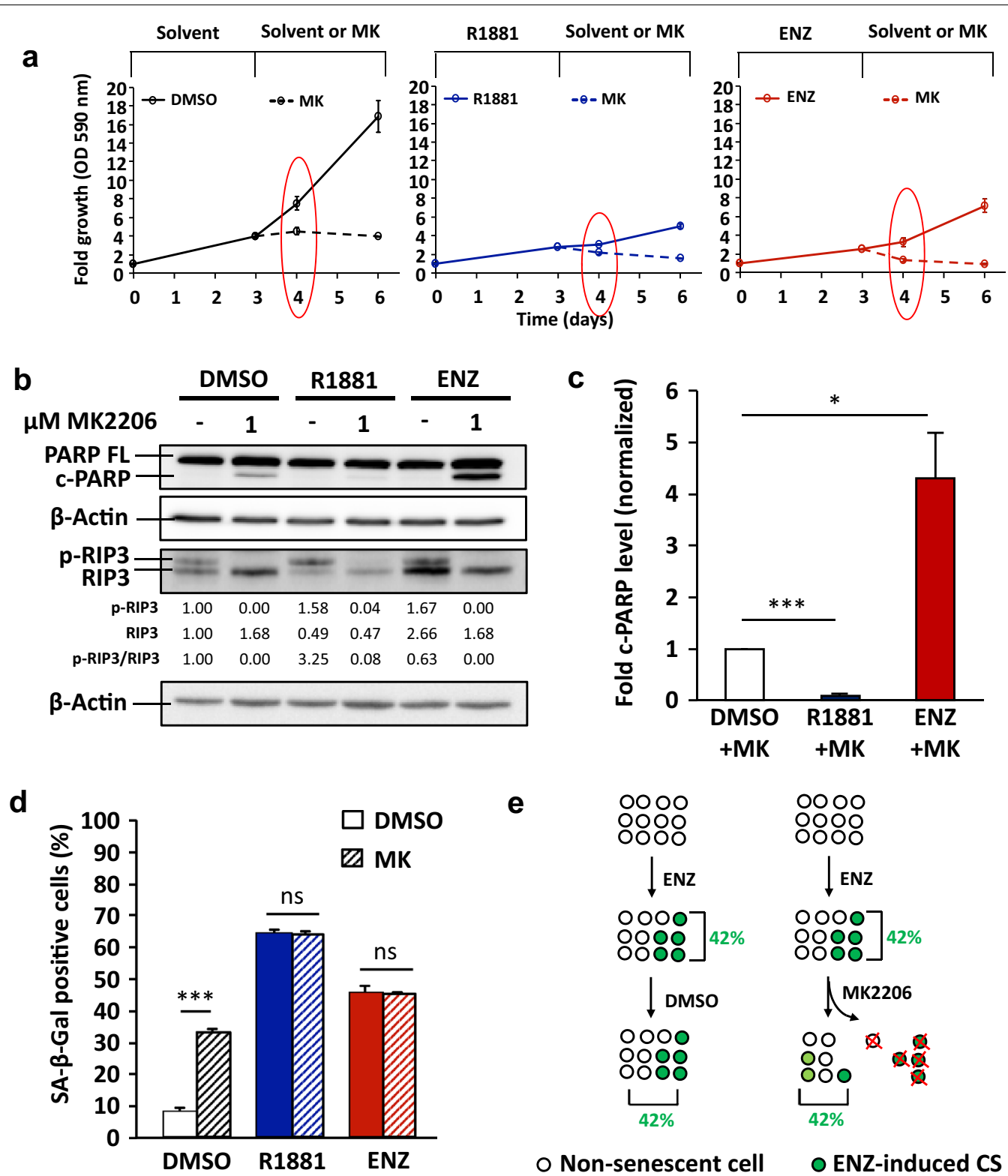

e

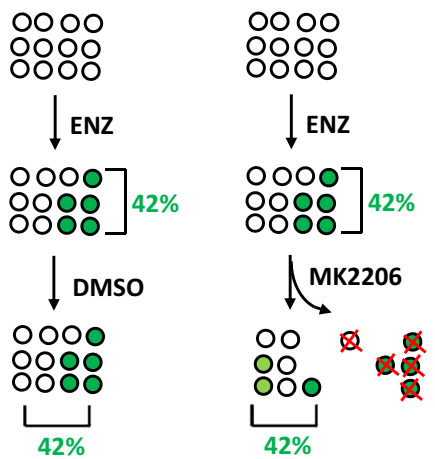

\section{O Non-senescent cell O ENZ-induced CS \\ O MK-induced CS $\times$ MK-induced apoptosis}

Fig. 4 AR antagonist-induced cellular senescent PCa LNCaP cells are sensitive to apoptosis induction by MK2206. LNCaP cells were treated for $72 \mathrm{~h}$ with $1 \mathrm{nM}$ R1881, $10 \mu \mathrm{M} \mathrm{ENZ,} \mathrm{or} 0.1 \%$ DMSO as solvent control. After that, the AR ligands were removed. Fresh medium with $0.1 \%$ DMSO or 1 MM MK2206 was added and further incubated for additional $72 \mathrm{~h}$. a Growth of LNCaP cells was analysed by crystal violet staining and OD $590 \mathrm{~nm}$ measurement. Values obtained from day 0 were set arbitrarily as 1. Line graphs are shown as mean \pm standard deviation $(n=2)$. Red circles indicate the time point of protein extractions. $\mathbf{b}$ The protein extraction was performed after $24 \mathrm{~h}$ treatment with MK2206. Detection of full-length PARP (PARP FL), cleaved PARP (c-PARP), RIP3, and phosphorylated RIP3 (p-RIP3) proteins was performed by Western blotting and normalized to $\beta$-Actin levels. Upper and middle numbers indicate normalized p-RIP3 and RIP3 band intensities. Lower numbers indicate the ratios of p-RIP3 versus RIP3 levels. c Quantification of fold c-PARP levels normalized to $\beta$-Actin from Western blotting data. Values obtained from DMSO + MK were set arbitrarily as 1. Bar graphs are shown as mean \pm SEM $(n=3)$. d Percentage of SA- $\beta$-Gal positive stained cells after $24 \mathrm{~h}$ treatment with MK2206. Bar graphs are shown as mean \pm SEM $(n=3)$. e A schematic figure illustrates an unchanged/compensated percentage level of SA- $\beta$-Gal positive cells under MK2206 treatment of ENZ treated cell. Numbers represent the calculated percentage of SA- $\beta$-Gal positive cells 


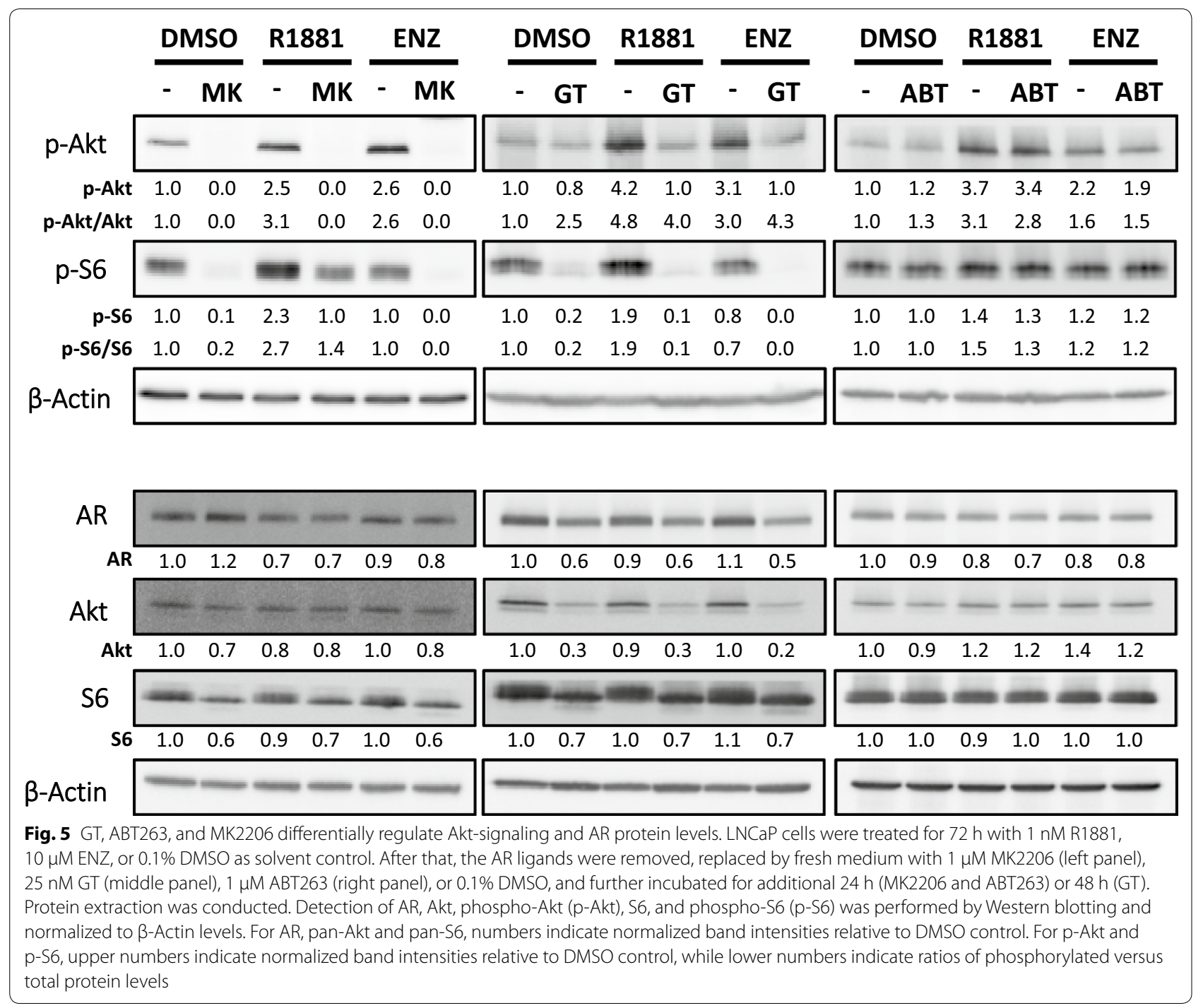

S6), whereas no significant change is observed by antagonist treatment.

Furthermore, phosphorylation of both Akt and S6, a downstream target of Akt as an indicator of Akt activity, were also analyzed (Fig. 5). Both phospho-Akt (p-Akt) and phospho-S6 (p-S6) protein levels are induced after SAL treatment. Interestingly, p-S6 level was not enhanced by ENZ suggesting a distinction between AR agonist- and antagonist-induced cellular senescence. This also indicates that Akt-S6 pathway is more active in AR agonist-treated cells (Fig. 5). Taken together, the expression of Bcl-2 family members, p-Akt, and p-S6 levels indicate that pro-survival/anti-apoptotic pathways are differentially regulated between AR agonist- and antagonist-induced cellular senescence.

Next, the effects of MK2206, GT, and ABT263 were analyzed on the pro-survival Akt-S6 pathway. After induction of cellular senescence by AR ligands, as expected, MK2206 potently reduces p-Akt levels (Fig. 5). Surprisingly, p-S6 levels, albeit decreased, remained high under MK2206 treatment in SAL-pretreated condition, suggesting that the activation of the downstream target of Akt, p-S6, is not fully blocked by MK2206 (Fig. 5). Hence, the data also indicate that the p-S6 level might be regulated in part by AR ligand, independent of Aktphosphorylation. Notably, p-S6 itself, besides Akt, has also been implicated in cell survival [36-38]. MEFs with phospho-defective/unphosphorylatable S6 $\left(\mathrm{S}^{\mathrm{P}-1-}\right)$ were more sensitive to apoptotic inducers than wild-type MEFs [37, 38]. This might explain our observation that SAL-induced cellular senescent cells exhibit resistance to MK2206.

Interestingly, GT treatment inhibits Akt-signaling as well (Fig. 5). In line with this, Akt, p-Akt, and p-S6 
protein levels were downregulated by GT. Although GT does not reduce p-Akt level as strong as MK2206, p-S6 level is dramatically reduced by GT (Fig. 5). This suggests that the downstream Akt-signaling such as p-S6 is more effectively inhibited by GT compared to MK2206. Considering the possibility that the survival of SAL-treated cells relies on elevated p-S6 levels, reducing p-S6 levels by GT will potently induce apoptosis. This might explain the previous observation that GT enhances apoptosis after AR agonist-induced cellular senescence.

Unlike MK2206 and GT, the inhibitor of the Bcl-2 family ABT263 does not interfere with Akt-S6 pathway (Fig. 5). Both p-Akt and p-S6 levels remain similar with or without ABT263 treatment. Taken together, the results suggest that both MK2206 and GT distinctly inhibit Aktsignaling, while ABT263 seems not to affect this pathway.

\section{GT reduces AR protein expression, while ABT263 and MK2206 exhibit no effect}

It is known that the AR is required for androgen-sensitive PCa cell survival. In line with this, AR knockdown mediates apoptosis in LNCaP cells [39]. Therefore, we analyzed AR protein level after GT, ABT263, and MK2206 treatment. Our data suggest that both MK2206 and ABT263 do not alter AR protein level (Fig. 5 and Additional file 1: Fig. S2). In contrast, GT reduces AR protein level regardless of the pretreatment with either AR agonist or antagonist (Fig. 5 and Additional file 1: Fig. S2). Since AR is a HSP90 client [40-42], the reduction of AR protein by GT is expected.

Taken together, our data suggest that the three inhibitors GT, ABT263, and MK2206 exhibit distinct mechanisms in AR ligand-induced cellular senescence. Mechanistically, GT treatment results in both reduction of AR protein level and inhibition of Akt-signaling. MK2206 does not reduce AR protein level but potently inhibits Akt phosphorylation, while ABT263 does neither affect AR protein nor Akt-signaling.

\section{Discussion}

Cellular senescence has been firstly introduced as an anti-cancer purpose, however, the effects of senescent cells on the tumor microenvironment via SASP factors have emerged [16-19, 43]. SASP can mediate paracrine effects on neighboring non-senescent cells and might act as tumor promoter. Moreover, senescent cells are hypothesized to have upregulated pro-survival/anti-apoptotic networks [20]. Hence, it leads to development and characterization of senolytic agents to overcome specific prosurvival pathways in order to eliminate senescent cells.

In this study, we analyzed pro-survival pathways dependent on either AR agonist- or antagonist-induced cell senescence. First, we show that AR agonist R1881 at supraphysiological levels or the antagonist ENZ is capable of inducing cellular senescence but not apoptosis in the androgen-sensitive PCa LNCaP cells. We hypothesized that SAL or ENZ causes senescent cells to activate or upregulated distinct pro-survival/anti-apoptotic pathways. Our results indicate that the Akt-S6 pathway is more activated by AR agonist-induced cellular senescence compared to antagonist. Notably on the one hand, SAL induces phosphorylation of both Akt and S6. On the other hand, ENZ induces phosphorylation of Akt but not S6. Furthermore, in contrast to antagonist, AR agonist regulates the expression of $\mathrm{Bcl}-2$ family members ( $B C L 2$ and $B C L 2 L 1$ ). These data suggest that the pro-survival/ anti-apoptotic pathways are distinct between AR agonistand antagonist-induced cellular senescent LNCaP cells. Therefore, a suitable senolytic compound for particular survival pathway must be identified.

Using inhibitors of these pathways indicated senolytic activity. Interestingly, our results reveal that treatment with Akt inhibitor MK2206 or HSP90 inhibitor GT exhibited distinct senolytic effects depending on the type of AR ligand, whereas no senolytic activity was observed for the Bcl-2 family inhibitor ABT263. In line with this, induction of the programmed cell death apoptosis but not necroptosis is observed as the underlying mechanism.

MK2206 is a highly selective allosteric Akt inhibitor [29] and to our knowledge, has not yet been described as a senolytic agent. Our data suggest that in contrast to AR agonist, the antagonist-induced cellular senescent PCa LNCaP cells are sensitive to apoptosis induction by MK2206. This demonstrates a novel role of MK2206 as senolytic compound for AR antagonist-treated LNCaP cells. In line with our findings, Pilling and Hwang (2019) showed that ENZ treatment induces phosphorylation of $\mathrm{BAD}$ (p-BAD) leading to inactivation of $\mathrm{BAD}$, a proapoptotic factor [35]. Moreover, co-treatment of MK2206 and ENZ inhibit p-BAD, which was not observed with the treatment of MK2206 alone. The combination treatment resulted in an enhanced apoptosis when compared to MK2206 alone [35]. In case of antagonist-induced senescence, the Akt-BAD pathway might explain the antagonist-specific senolysis by MK2206.

In case of SAL-induced cellular senescence, we propose that the resistance to MK2206-mediated apoptosis is explained by the remaining high p-S6 levels despite Akt inhibition. Thus, we suggest that SAL treatment bypassed Akt and phosphorylated directly or indirectly S6. The p-S6 itself has also been implicated with cell survival [36-38]. The $\mathrm{S6}^{\mathrm{P}-1-}$ mediates sensitivity to TRAIL-, etoposide-, or MG132-induced apoptosis in MEFs [37, $38]$, thus suggesting that $\mathrm{p}-\mathrm{S} 6$ is a critical pro-survival factor. Therefore, we propose that despite treatment with 
the Akt inhibitor MK2206, SAL induces phosphorylation of S6 as an underlying mechanism for resistance against apoptosis by MK2206.

Further evidence supports the notion that AR agonist- and antagonist-induced cellular senescence address different intracellular factors. The HSP90 inhibitor GT selectively mediates high senolytic activity after AR agonist- but not antagonist-induced cellular senescence. In line with this, cleaved PARP induction was significantly enhanced by GT treatment after SAL-induced cellular senescence, indicating that AR agonist-treated LNCaP cells are sensitive to GT-induced apoptosis.

We hypothesize that the apoptosis induction by GT may rely on the synergistic reduction of AR protein level and inhibition of Akt-signaling. AR is required for androgen-sensitive PCa cell survival [39] and both AR and Akt are HSP90 clients [40-42, 44].

Interestingly, GT does not completely abolish the p-Akt level as observed with MK2206, however, p-S6 level is dramatically reduced by GT after SAL-induced cellular senescence. We hypothesize that the survival of AR agonist-treated LNCaP cells may also rely more on the upregulated/activated p-S6. Hence, AR agonist-induced cellular senescent cells are more sensitive to apoptosis when $\mathrm{p}-\mathrm{S} 6$ is reduced.

ABT263 selectively induced apoptosis in senescent HUVECs and IMR90 cells, while no senolytic effect was observed in TW-37 cell types [45] suggesting a cell-type dependency. Surprisingly, our data suggest that ABT263 has no senolytic effect with either AR agonist- or antagonist-induced cellular senescence in LNCaP cells. Treatment with ABT263 in AR ligand-pretreated cells reveals significantly less cleaved PARP levels than the controltreated condition. Furthermore, treatment with ABT263 neither reduced AR protein nor inhibited Akt-signaling. The data further indicate that the AR ligand-induced cellular senescent LNCaP cells are more resistant to ABT263-mediated apoptosis than control.

We presume that it may depend very much on which pro-survival pathway is induced in senescent cells to use a specific senolytic compound. It is possible that between tumor types and within the heterogeneity of a tumor, a particular pro-survival pathway is activated by a senescence-inducing agent.

On the one hand, PCa therapy is currently relying on inhibition of the AR-signaling by AR antagonists as the major forms of hormone therapy. On the other hand, another option like BAT using SAL has recently been emerged. Either AR antagonist or SAL induces cellular senescence in $\mathrm{PCa}$, including ex vivo in $\mathrm{PCa}$ patient samples $[9,13]$. It is possible that the initial tumor growth reduction by therapy with AR antagonist or BAT is due to induction of cellular senescence. However, senescence might subsequently influence and stimulate neighboring tumor and non-tumor cells via SASP. Therefore, it might be useful to combine AR antagonist or BAT with senolytic compounds. Our data indicate that Akt inhibitor along with AR antagonist or HSP90 inhibitor along with SAL treatment may be beneficial therapeutic options.

\section{Conclusion}

In conclusion, our data indicate that AR ligand-induced cellular senescent LNCaP cells exhibit different upregulated pro-survival pathways depending on the type of AR ligand used. Treatment with GT or MK2206 after AR ligand-induced cellular senescence exhibits distinct senolytic effects depending on the type of AR ligand and inhibitor, while ABT263 lacks senolytic effect. This suggests that senolytic activity of each senolytic compound can be limited when senescence is induced by different mechanisms. Thus, a suitable senolytic compound for a particular situation/treatment should be considered.

\section{Materials and methods}

Cell culture and treatments

LNCaP cells [46] were cultured in RPMI 1640 medium (Gibco Life Technologies) supplemented with 5\% fetal calf serum (FCS), $100 \mathrm{U} / \mathrm{ml}$ penicillin, $100 \mu \mathrm{g} / \mathrm{ml}$ streptomycin, $1 \mathrm{mM}$ sodium pyruvate, and $25 \mathrm{mM}$ HEPES $\mathrm{pH}$ 7.5.

LNCaP cells were seeded in an appropriate amount for each experiment in cell culture plates. After $48 \mathrm{~h}$ of incubation, the cells were treated for $72 \mathrm{~h}$ with $1 \mathrm{nM}$ R1881, $10 \mu \mathrm{M}$ ENZ, or 0.1\% DMSO as solvent control. After that, the medium including AR ligand was removed and refreshed by fresh medium with $25 \mathrm{nM}$ GT, $1 \mu \mathrm{M}$ ABT263, $1 \mu \mathrm{M}$ MK2206, or 0.1\% DMSO for the next $96 \mathrm{~h}$. The cells were maintained in a $5 \% \mathrm{CO} 2$, humidified atmosphere at $37^{\circ} \mathrm{C}$.

\section{Cellular senescence assays}

The assays were performed with 6-well plates, and the cells were seeded at 25,000 cells per well. The staining and detection were performed as described previously [47-49]. The percentage of SA- $\beta-$ Gal positive cells was calculated by counting at least $3 \times 200$ cells per well and at least 2 wells per treatment under a light microscope.

\section{Growth assays}

The assays were performed with 6-well plates, and the cells were seeded at 20,000 cells per well. The growth assays were analyzed by crystal violet staining and OD $590 \mathrm{~nm}$ measurement, where the values obtained at day 0 were set arbitrarily as 1 . The staining and detection were performed as described previously [48, 49]. 


\section{Antibodies and Western blotting}

For protein extraction, the assays were performed with $10 \mathrm{~cm}$ cell culture plates, and the cells were seeded at 500,000 cells per dish for MK2206 experiments and at 120,000 cells per dish for GT and ABT263 experiments. The whole-cell lysate preparation was adapted from Esmaeili et al. (2016) [48, 49]. Briefly, the cells were lysed using NETN buffer ( $100 \mathrm{mM} \mathrm{NaCl}, 20 \mathrm{mM}$ Tris/ $\mathrm{HCl} \mathrm{pH} \mathrm{8.0,} 1$ mM EDTA, 1\% NP-40) supplemented with phosphatase inhibitors $(5 \mathrm{mM} \mathrm{NaF}, 100 \mu \mathrm{M} \mathrm{Na}$ VO4, $10 \mathrm{mM} \beta$-Glycerophosphate) and followed by three cycles of freezing (in liquid nitrogen) and thawing (in a $37^{\circ} \mathrm{C}$ water bath). The protein extracts were separated by SDS-PAGE. The primary antibodies used for immunodetection were Akt (Cell Signaling, 4685S), AR (Biogenex, 256M), $\beta$-Actin (Abcam, ab6276), phosphorylated Akt (S473) (Cell Signaling, 4058S), cleaved PARP (Cell Signaling, 9546S), RIP3 (Abcam, ab56164), S6 (Cell Signaling, 2217S), and phosphorylated S6 (S235/236) (Cell Signaling, 2211S). Horseradish peroxidase-conjugated antimouse IgG (Cell Signaling, 7076S) or anti-rabbit IgG (Cell Signaling, 7074S) were used as secondary antibodies. The detection was performed by ImageQuant ${ }^{\mathrm{TM}} \mathrm{LAS}$ 4000 (GE Healthcare Bio-Sciences AB).

To verify the detection of phosphorylated RIP3, the whole-cell lysate preparation was performed with NETN buffer with or without phosphatase inhibitors. The protein extracts were incubated at $37^{\circ} \mathrm{C}$ for $3 \mathrm{~h}$ with or without alkaline phosphatase (FAST AP) (Thermo Scientific).

\section{Quantitative reverse transcription PCR (qRT-PCR)}

The assays were performed with RNA isolated from $10 \mathrm{~cm}$ cell culture dishes, and the cells were seeded at 500,000 cells per dish. The total RNA extraction was performed using peqGOLD TriFast (Peqlab) according to the manufacturer's protocol. Two-step qRT-PCR was performed as described previously $[48,49]$ with gene specific primers. TBP mRNA is served as the housekeeping gene for normalization. The primer sequences are listed as $5^{\prime} \rightarrow 3^{\prime}$ : TBP: fwd: GGCGTGTGAAGATAA CCCAAGG, rev: CGCTGGAACTCGTCTCACT, BCL2: fwd: CATGTGTGTGGAGAGCGTCAA, rev: GCCGGT TCAGGTACTCAGTCA, BCL2L1: fwd: AACATCCCA GCTTCACATAACCCC, rev: GCGACCCCAGTTTAC TCCATCC, BCL2L2: fwd: ACCCGTGAGATCCCTAAC CTG, rev: CAGCTCCACAGACATAACCCT, CDKN2A (p14 ${ }^{\mathrm{ARF}}$ ): fwd: CCTGGAGGCGGCGAGAAC, rev: AGT AGCATCAGCACGAGGGC, CDKN2A (p16 $\left.{ }^{\mathrm{INK4a}}\right)$ : fwd: CTTGCCTGGAAAGATACCG, rev: CCCTCCTCT TTCTTCCTCC, CDKN1A: fwd: TCGACTTTGTCA CCGAGACACCAC, rev: CAGGTCCACATGGTCTTC CTCTG, CDKN1B: fwd: GGCCTCAGAAGACGTCAA
AC, rev: ACAGGATGTCCATTCCATGA, KLK3: fwd: GAGGCTGGGAGTGCGAGAAG, rev: TTGTTCCTG ATGCAGTGGGC.

\section{Statistical analysis}

For statistical analysis, a two-tailed unpaired Student's $t$ test was performed using the GraphPad Prism 8.0 software, which were calculated from the mean, standard deviation, standard error of mean (SEM), and number of replicates (n). A 95\% confidence interval ( $\mathrm{p}$-value $(\mathrm{p})<0.05)$ was considered as statistically significant $(*)$ between two subject groups. A $99 \%$ confidence interval $(\mathrm{p}<0.01)$ and a $99.9 \%$ confidence interval $(\mathrm{p}<0.001)$ were indicated by two $\left.{ }^{(* *)}\right)$ and three stars $\left({ }^{* * * * *)}\right)$, respectively. Western blotting analysis was performed at least for biological duplicates to shown regulation at protein levels.

\section{Supplementary information}

Supplementary information accompanies this paper at https://doi. org/10.1186/s13578-020-00422-2.

Additional file 1: Fig. S1. Enzalutamide treatment significantly induces CDKN2A (p16 ${ }^{\text {INK4a }}$ ) expression. Fig. S2. GT, ABT263, and MK2206 inhibit LNCaP cells proliferation through apoptosis induction in a concentration dependent manner. Fig. S3. p-RIP3 is dephosphorylated by alkaline phosphatase (FAST AP). Fig. S4. GT enhances detachment of cells after androgen-induced cellular senescence. Fig. S5. ABT263 and MK2206 induce LNCaP cell detachment. Fig. S6. Androgen regulates $\mathrm{BCl}-2$ family members transcription levels.

\section{Abbreviations}

AR: Androgen receptor; BAT: Bipolar androgen therapy; DHT: Dihydrotestosterone; ENZ: Enzalutamide; GT: Ganetespib; HSP90: Heat shock protein 90; PCa: Prostate cancer; R1881: Methyltrienolone; SA- $\beta-G a l$ : Senescence-associated $\beta$-galactosidase; SAL: Supraphysiological androgen level; SASP: Senescenceassociated secretory phenotype.

\section{Acknowledgements}

This work was supported by the German Academic Exchange Service (DAAD; Deutscher Akademischer Austauschdienst) (TP), Universitätsklinikum Jena, and Astellas Pharma GmbH (AB). We acknowledge support by the German Research Foundation and the Open Access Publication Fund of the Thueringer Universitaets- und Landesbibliothek Jena Projekt-Nr. 433052568.

\section{Authors' contributions}

TP, MFS, and MCCME performed the experiments and analyzed the data. TP and $A B$ wrote the manuscript. GL, MK, and ASK edited the manuscript. $A B$ conceived and supervised this study, provided technical supports, and revised the manuscript. All authors read and approved the final manuscript.

\section{Availability of data and materials}

All data generated and analyzed for this study are included in this published article.

Ethics approval and consent participate

Not applicable.

Consent for publication

Not applicable. 


\section{Competing interests}

The authors declare that they have no competing interests.

\section{Author details}

${ }^{1}$ Institute of Human Genetics, Jena University Hospital, Am Klinikum 1, 07740 Jena, Germany. ${ }^{2}$ Department of Hematology and Medical Oncology, Jena University Hospital, Jena, Germany. ${ }^{3}$ Laboratory for Experimental Immunology of the Eye, Department of Ophthalmology, University Hospital Cologne, Cologne, Germany.

Received: 12 February 2020 Accepted: 17 April 2020

Published online: 25 April 2020

\section{References}

1. Jemal A, Siegel R, Ward E, Murray T, Xu J, Thun MJ. Cancer statistics, 2007. CA Cancer J Clin. 2007;57(1):43-66.

2. Siegel RL, Miller KD, Jemal A. Cancer statistics, 2019. CA Cancer J Clin. 2019;69(1):7-34.

3. Lonergan PE, Tindall DJ. Androgen receptor signaling in prostate cancer development and progression. J Carcinog. 2011;10:20.

4. Decker KF, Zheng D, He Y, Bowman T, Edwards JR, Jia L. Persistent androgen receptor-mediated transcription in castration-resistant prostate cancer under androgen deprived conditions. Nucleic Acids Res. 2012;40(21):10765-79.

5. Perner S, Cronauer MV, Schrader AJ, Klocker H, Culig Z, Baniahmad A. Adaptive responses of androgen receptor signaling in castration-resistant prostate cancer. Oncotarget. 2015:6(34):35542-55.

6. Lakshmana G, Baniahmad A. Interference with the androgen receptor protein stability in therapy-resistant prostate cancer. Int J Cancer 2019;144(8):1775-9.

7. Teply BA, Wang H, Luber B, Sullivan R, Rifkind I, Bruns A, Spitz A, DeCarli M, Sinibaldi V, Pratz CF, Lu C, Silberstein JL, Luo J, Schweizer MT, Drake CG, Carducci MA, Paller CJ, Antonarakis ES, Eisenberger MA, Denmeade SR. Bipolar androgen therapy in men with metastatic castration-resistant prostate cancer after progression on enzalutamide: an open-label, phase 2, multicohort study. Lancet Oncol. 2018;19(1):76-86.

8. Denmeade SR. Bipolar androgen therapy in the treatment of prostate cancer. Clin Adv Hematol Oncol. 2018;16(6):408-11.

9. Hessenkemper W, Roediger J, Bartsch S, Houtsmuller AB, van Royen ME, Petersen I, Grimm MO, Baniahmad A. A natural androgen receptor antagonist induces cellular senescence in prostate cancer cells. Mol Endocrinol. 2014:28(11):1831-40.

10. Roell D, Rösler TW, Hessenkemper W, Kraft F, Hauschild M, Bartsch S, Abraham TE, Houtsmuller AB, Matusch R, van Royen ME, Baniahmad A. Halogen-substituted anthranilic acid derivatives provide a novel chemical platform for androgen receptor antagonists. J Steroid Biochem Mol Biol. 2019;188:59-70.

11. Fousteris MA, Schubert U, Roell D, Roediger J, Bailis N, Nikolaropoulos SS, Baniahmad A, Giannis A. 20-Aminosteroids as a novel class of selective and complete androgen receptor antagonists and inhibitors of prostate cancer cell growth. Bioorg Med Chem. 2010;18(19):6960-9.

12. Mirochnik Y, Veliceasa D, Williams L, Maxwell K, Yemelyanov A, Budunova I, Volpert OV. Androgen receptor drives cellular senescence. PLoS ONE. 2012;7(3):e31052.

13. Roediger J, Hessenkemper W, Bartsch S, Manvelyan M, Huettner SS, Liehr T, Esmaeili M, Foller S, Petersen I, Grimm MO, Baniahmad A. Supraphysiological androgen levels induce cellular senescence in human prostate cancer cells through the Src-Akt pathway. Mol Cancer. 2014;13:214.

14. Qin S, Schulte BA, Wang GY. Role of senescence induction in cancer treatment. World J Clin Oncol. 2018:9(8):180-7.

15. Collado M, Gil J, Efeyan A, Guerra C, Schuhmacher AJ, Barradas M, Benguría A, Zaballos A, Flores JM, Barbacid M, Beach D, Serrano M. Tumour biology: senescence in premalignant tumours. Nature. 2005;436(7051):642.

16. Campisi J. Aging, cellular senescence, and cancer. Annu Rev Physiol. 2013;75:685-705.

17. Campisi J. Cell biology: the beginning of the end. Nature. 2014;505(7481):35-6.

18. Coppé JP, Patil CK, Rodier F, Sun Y, Muñoz DP, Goldstein J, Nelson PS, Desprez PY, Campisi J. Senescence-associated secretory phenotypes reveal cell-nonautonomous functions of oncogenic RAS and the p53 tumor suppressor. PLoS Biol. 2008;6(12):2853-68.

19. Coppé JP, Desprez PY, Krtolica A, Campisi J. The senescence-associated secretory phenotype: the dark side of tumor suppression. Annu Rev Pathol. 2010;5:99-118.

20. Wong J, Qudrat A, Al Mosabbir A, Truong K. Advances in Senotherapies. In: Rizvi SI, Çakatay U, editors. Molecular basis and emerging strategies for anti-aging interventions. Singapore: Springer; 2018. p. 67-82.

21. Fuhrmann-Stroissnigg $H$, Ling YY, Zhao J, McGowan SJ, Zhu Y, Brooks RW, Grassi D, Gregg SQ, Stripay JL, Dorronsoro A, Corbo L, Tang P, Bukata C, Ring N, Giacca M, Li X, Tchkonia T, Kirkland JL, Niedernhofer LJ, Robbins PD. Identification of HSP90 inhibitors as a novel class of senolytics. Nat Commun. 2017;8(1):422

22. Fuhrmann-Stroissnigg $\mathrm{H}$, Niedernhofer LJ, Robbins PD. Hsp90 inhibitors as senolytic drugs to extend healthy aging. Cell Cycle. 2018;17(9):1048-55.

23. Zhu Y, Tchkonia T, Fuhrmann-Stroissnigg $H$, Dai HM, Ling YY, Stout MB Pirtskhalava T, Giorgadze N, Johnson KO, Giles CB, Wren JD, Niedernhofer LJ, Robbins PD, Kirkland JL. Identification of a novel senolytic agent, navitoclax, targeting the Bcl-2 family of anti-apoptotic factors. Aging Cell. 2016;15(3):428-35.

24. Hernandez-Segura A, de Jong TV, Melov S, Guryev V, Campisi J, Demaria M. Unmasking transcriptional heterogeneity in senescent cells. Curr Biol. 2017;27(17):2652-60.

25. Handa RJ, Pak TR, Kudwa AE, Lund TD, Hinds L. An alternate pathway for androgen regulation of brain function: activation of estrogen receptor beta by the metabolite of dihydrotestosterone, $5 a$-androstane 3 $\beta, 17 \beta$ diol. Horm Behav. 2008;53(5):741-52.

26. Xie J, Xu X, Yin P, Li Y, Guo H, Kujawa S, Chakravarti D, Bulun S, Kim JJ, Wei JJ. Application of ex vivo spheroid model system for the analysis of senescence and senolytic phenotypes in uterine leiomyoma. Lab Invest. 2018;98(12):1575-87.

27. Schlomovitz I, Zargarian S, Erlich Z, Edry-Botzer L, Gerlic M. Distinguishing necroptosis from apoptosis. Methods Mol Biol. 2018;1857:35-51.

28. Song G, Ouyang G, Bao S. The activation of Akt/PKB signaling pathway and cell survival. J Cell Mol Med. 2005;9(1):59-71.

29. Hirai H, Sootome H, Nakatsuru Y, Miyama K, Taguchi S, Tsujioka K, Ueno Y, Hatch H, Majumder PK, Pan BS, Kotani H. MK-2206, an allosteric Akt inhibitor, enhances antitumor efficacy by standard chemotherapeutic agents or molecular targeted drugs in vitro and in vivo. Mol Cancer Ther. 2010;9(7):1956-67.

30. Yap TA, Yan L, Patnaik A, Fearen I, Olmos D, Papadopoulos K, Baird RD, Delgado L, Taylor A, Lupinacci L, Riisnaes R, Pope LL, Heaton SP, Thomas G, Garrett MD, Sullivan DM, de Bono JS, Tolcher AW. First-in-man clinical trial of the oral pan-AKT inhibitor MK-2206 in patients with advanced solid tumors. J Clin Oncol. 2011;29(35):4688-95.

31. Lara PN Jr, Longmate J, Mack PC, Kelly K, Socinski MA, Salgia R, Gitlitz B, Li T, Koczywas M, Reckamp KL, Gandara DR. Phase II Study of the AKT Inhibitor MK-2206 plus erlotinib in patients with advanced non-small cell lung cancer who previously progressed on erlotinib. Clin Cancer Res. 2015;21(19):4321-6.

32. Floc'h N, Kinkade CW, Kobayashi T, Aytes A, Lefebvre C, Mitrofanova A, Cardiff RD, Califano A, Shen MM, Abate-Shen C. Dual targeting of the Akt/mTOR signaling pathway inhibits castration-resistant prostate cancer in a genetically engineered mouse model. Cancer Res. 2012;72(17):4483-93.

33. Zhang W, Haines BB, Efferson C, Zhu J, Ware C, Kunii K, Tammam J, Angagaw M, Hinton MC, Keilhack H, Paweletz CP, Zhang T, Winter C, Sathyanarayanan S, Cheng J, Zawel L, Fawell S, Gilliland G, Majumder PK. Evidence of mTOR activation by an AKT-independent mechanism provides support for the combined treatment of PTEN-deficient prostate tumors with mTOR and AKT inhibitors. Transl Oncol. 2012;5(6):422-9.

34. Al-Saffar NMS, Troy H, Wong Te Fong AC, Paravati R, Jackson LE, Gowan S, Boult JKR, Robinson SP, Eccles SA, Yap TA, Leach MO, Chung YL. Metabolic biomarkers of response to the AKT inhibitor MK-2206 in pre-clinical models of human colorectal and prostate carcinoma. Br J Cancer. 2018;119(9):1118-28.

35. Pilling $A B$, Hwang $C$. Targeting prosurvival $B C L 2$ signaling through Akt blockade sensitizes castration-resistant prostate cancer cells to enzalutamide. Prostate. 2019;79(11):1347-59. 
36. Meyuhas O. Ribosomal protein S6 phosphorylation: four decades of research. Int Rev Cell Mol Biol. 2015;320:41-73.

37. Jeon YJ, Kim IK, Hong SH, Nan H, Kim HJ, Lee HJ, Masuda ES, Meyuhas O, Oh BH, Jung YK. Ribosomal protein $\mathrm{S} 6$ is a selective mediator of TRAILapoptotic signaling. Oncogene. 2008;27(31):4344-52.

38. Wittenberg AD, Azar S, Klochendler A, Stolovich-Rain M, Avraham S, Birnbaum L, Binder Gallimidi A, Katz M, Dor Y, Meyuhas O. Phosphorylated ribosomal protein $\mathrm{S} 6$ is required for Akt-driven hyperplasia and malignant transformation, but not for hypertrophy, aneuploidy and hyperfunction of pancreatic $\beta$-cells. PLoS ONE. 2016;11(2):e0149995.

39. Yang Q, Fung KM, Day WV, Kropp BP, Lin HK. Androgen receptor signaling is required for androgen-sensitive human prostate cancer cell proliferation and survival. Cancer Cell Int. 2005;5(1):8.

40. Hessenkemper W, Baniahmad A. Chaperones for proper androgen action-a plethora of assistance to androgen receptor function. Horm Mol Biol Clin Investig. 2012;11(1):321-8.

41. He S, Zhang C, Shafi AA, Sequeira M, Acquaviva J, Friedland JC, Sang J, Smith DL, Weigel NL, Wada Y, Proia DA. Potent activity of the Hsp90 inhibitor ganetespib in prostate cancer cells irrespective of androgen receptor status or variant receptor expression. Int J Oncol. 2013;42(1):35-43.

42. Centenera MM, Carter SL, Gillis JL, Marrocco-Tallarigo DL, Grose RH, Tilley WD, Butler LM. Co-targeting AR and HSP90 suppresses prostate cancer cell growth and prevents resistance mechanisms. Endocr Relat Cancer. 2015;22(5):805-18.

43. Campisi J, d'Adda di Fagagna F. Cellular senescence: when bad things happen to good cells. Nat Rev Mol Cell Biol. 2007;8(9):729-40.

44. Zhang R, Luo D, Miao R, Bai L, Ge Q, Sessa WC, Min W. Hsp90-Akt phosphorylates ASK1 and inhibits ASK1-mediated apoptosis. Oncogene. 2005;24(24):3954-63.
45. Zhu Y, Doornebal EJ, Pirtskhalava T, Giorgadze N, Wentworth M, Fuhrmann-Stroissnigg H, Niedernhofer LJ, Robbins PD, Tchkonia T, Kirkland JL. New agents that target senescent cells: the flavone, fisetin, and the BCL-XL inhibitors, A1331852 and A1155463. Aging. 2017;9(3):955-63.

46. Protopopov Al, Li J, Winberg G, Gizatullin RZ, Kashuba VI, Klein G, Zabarovsky ER. Human cell lines engineered for tetracycline-regulated expression of tumor suppressor candidate genes from a frequently affected chromosomal region, 3p21. J Gene Med. 2002;4(4):397-406.

47. Dimri GP, Lee X, Basile G, Acosta M, Scott G, Roskelley C, Medrano EE, Linskens M, Rubelj I, Pereira-Smith O, et al. A biomarker that identifies senescent human cells in culture and in aging skin in vivo. Proc Natl Acad Sci USA. 1995;92:9363-7.

48. Esmaeili M, Jennek S, Ludwig S, Klitzsch A, Kraft F, Melle C, Baniahmad A. The tumor suppressor ING1 b is a novel corepressor for the androgen receptor and induces cellular senescence in prostate cancer cells. J Mol Cell Biol. 2016;8(3):207-20.

49. Esmaeili M, Pungsrinont T, Schaefer A, Baniahmad A. A novel crosstalk between the tumor suppressors ING1 and ING2 regulates androgen receptor signaling. J Mol Med. 2016;94(10):1167-79.

\section{Publisher's Note}

Springer Nature remains neutral with regard to jurisdictional claims in published maps and institutional affiliations.
Ready to submit your research? Choose BMC and benefit from:

- fast, convenient online submission

- thorough peer review by experienced researchers in your field

- rapid publication on acceptance

- support for research data, including large and complex data types

- gold Open Access which fosters wider collaboration and increased citations

- maximum visibility for your research: over 100M website views per year

At BMC, research is always in progress.

Learn more biomedcentral.com/submissions 